Annuaire suisse de politique de développement

26-2 | 2007

Financer le développement par la mobilisation des ressources locales

\title{
Aide budgétaire et réforme de la fiscalité : l'exemple du Mozambique
}

Jean-Luc Bernasconi

\section{OpenEdition}

\section{Journals}

Édition électronique

URL : http://journals.openedition.org/aspd/149

DOI : 10.4000/aspd. 149

ISSN : 1663-9669

Éditeur

Institut de hautes études internationales et du développement

Édition imprimée

Date de publication : 1 novembre 2007

Pagination : 215-216

ISBN : 978-2-88247-068-3

ISSN : 1660-5934

Référence électronique

Jean-Luc Bernasconi, « Aide budgétaire et réforme de la fiscalité : l'exemple du Mozambique »,

Annuaire suisse de politique de développement [En ligne], 26-2 | 2007, mis en ligne le 22 juin 2009,

consulté le 08 septembre 2020. URL : http://journals.openedition.org/aspd/149 ; DOI : https://doi.org/ 10.4000/aspd. 149 


\title{
Aide budgétaire et réforme de la fiscalité: l'exemple du Mozambique
}

\author{
Jean-Luc Bernasconi
}

A ssez rapidement, le SECO a porté une attention particulière aux efforts de réforme des administrations fiscales. Par ce biais, un double objectif est recherché: d'une part, contribuer au renforcement soutenable d'une source de financement du budget national qui devrait, à terme, permettre une sortie "réussie" des programmes d'aide budgétaire; d'autre part, chercher à soutenir la mise en place d'une véritable "fiscalité de développement»" à savoir un système où l'arbitraire et la corruption sont éliminés et où le poids de la fiscalité ne constitue pas un frein à l'investissement et à la croissance, tout en respectant des principes d'équité. Dans des pays où l'informel gère une part importante de l'économie, ces objectifs sont ambitieux et ne peuvent être atteints que sur le long terme. En général, on distingue entre la réforme de politique fiscale (par exemple la modification des taux d'imposition ou le passage à la taxe sur la valeur ajoutée - TVA) et les réformes administratives visant à renforcer la capacité des administrations à mettre en œuvre ces politiques, même si, en fin de compte, réformes politiques et administratives sont intimement liées. Les programmes soutenus par le SECO appartiennent principalement à cette seconde catégorie, même si la Suisse est aussi impliquée dans le dialogue de politique fiscale au travers des mécanismes de concertation de l'aide budgétaire.

Au Mozambique, comme dans beaucoup de pays africains, la politique fiscale de ces dernières années a été intimement liée à la politique commerciale. Les mesures de libéralisation commerciale ont comprimé les recettes douanières, qui représentaient jusqu'à peu la majorité des revenus budgétaires. La fiscalité domestique (impôts directs sur le revenu, taxes ou accises indirectes sur la consommation et recettes «non fiscales» telles que licences d'exploitation minière) se doit donc de compenser les pertes de la fiscalité de porte pour maintenir, voire augmenter le niveau de dépenses publiques prioritaires. A cette fin, le Mozambique s'est engagé dans un vaste programme de réforme fiscale à l'aube $\left.d u X x\right|^{e}$ siècle, en introduisant une TVA dès 1999, accompagnée par d'autres mesures de type administratif assez classiques pour améliorer l'efficacité de la perception de l'impôt: redéploiement des services en fonction de la taille des contribuables, amélioration des systèmes d'information sur les contribuables, réformes de l'imposition des revenus et des bénéfices, etc. La stratégie de développement du pays prévoit une augmentation de 0,5\% par an des recettes budgétaires sur la période 2005-2009. Par ailleurs, suivant en quelque sorte un modèle anglo-saxon, le Mozambique a décidé de regrouper tous ses services fiscaux depuis 2006 en une seule entité semi-autonome, l'autorité centrale de recettes (Autoridade Tributária Moçambicana, ATM). Qu'en est-il des résultats obtenus jusqu'ici? Le taux de pression fiscale, encore audessous de $10 \%$ du PIB à la fin des années 1990, s'est élevé progressivement pour atteindre $14,4 \%$ du PIB en 2006 , et cela malgré un niveau élevé de ce PIB. On peut donc se réjouir que l'effort fiscal n'ait en tout cas pas diminué, même avec les apports accrus d'aide budgétaire. Ces taux restent cependant faibles, même en comparaison régionale. II faut se

1 La "fiscalité» est ici comprise au sens large, c'est-à-dire comme incluant tous types de recettes budgétaires: impôts, droits, accises, de même que les royalties dérivées de droits d'exploitation de ressources naturelles par exemple. 
garder toutefois de procéder à une augmentation des taux d'imposition ou à la création de nouveaux impôts, qui ne permettraient sans doute que des gains à court très court terme et se révéleraient contre-productives au-delà. L'effort de réformes administratives doit être poursuivi, notamment avec le renforcement de I'ATM. Par ailleurs, des faiblesses dans la mise en œuvre du système existant qui pénalisent le secteur productif doivent être corrigées (par exemple le remboursement des crédits de TVA). Ensuite, un rééquilibrage du système par la refonte du système d'exonération s'impose également. La politique assez agressive en matière de remises fiscales pour lancer le programme de promotion des investissements étrangers devra être évaluée régulièrement. Finalement, les réformes fiscales seront rendues plus complexes par le processus de décentralisation qui se déroule en parallèle et qui induit une redéfinition de la souveraineté fiscale entre niveaux administratifs. C'est sur ces fronts multiples que le SECO et les quelques autres partenaires actifs dans ce domaine sont prêts à poursuivre leur appui aux autorités mozambicaines. Sur un horizon de cinq à dix ans, on escompte ainsi une augmentation de la pression fiscale jusqu'à $15 \%$, puis $20 \%$ du PIB. 